\title{
Effects of providing total mixed rations indoors and on pasture on the behavior of lactating dairy cattle and their preference to be indoors or on pasture
}

\author{
G. L. Charlton, ${ }^{*} \dagger$ S. M. Rutter,${ }^{* 1}$ M. East, $\dagger$ and L. A. Sinclair ${ }^{*}$ \\ ${ }^{*}$ Animal Science Research Centre, Harper Adams University College, Shropshire, TF10 8NB, UK \\ †Agriculture Department, Reaseheath College, Cheshire, CW5 6DF, UK
}

\begin{abstract}
Grazing is considered a normal behavior for dairy cattle, although they may not be able to meet their nutritional requirements from grazing alone, and so to sustain higher yields requires access to a total mixed ration (TMR). The study aim was to provide dairy cows with access to TMR indoors and on pasture to establish influence on behavior and preference for each location. The study took place from August to November, 2009, using 36 late-lactation Holstein-Friesian dairy cows. The cows were allocated to 1 of $326-\mathrm{d}$ study periods (n $=12 \times 3)$. Within each period the cows were further divided into a control $(\mathrm{n}=6)$ or treatment $(\mathrm{n}=6)$ group using a crossover design, where the cows were changed between the control and treatment group after $13 \mathrm{~d}$. Treatment cows had access to TMR indoors and on pasture, whereas control cows only had access to TMR indoors. Following a.m. and p.m. milkings the cows were taken to a point equidistant between indoors and pasture and given the choice of going to pasture (1.5 ha) or to a freestall barn. Between milkings the cows had free access between the locations. Initial choice was recorded and a video camera was used to record time spent in each location. Behavior observations were recorded to establish how the cows spent their time during the day. To determine what factors influenced preference, weather conditions, milk yield, body condition score, and lameness were recorded. Initially, the cows chose indoors following milking (96.4 \pm $0.80 \%)$. Overall, the cows expressed a partial preference for pasture $(71.1 \pm 1.82 \%)$, which was different from 100,50 , and $0 \%$. Study period influenced preference with cows spending less time on pasture as the season progressed (86.7 vs. 68.3 vs. $58.3 \%$ for study periods 1 , 2 , and 3 , respectively). Providing the cows with TMR outdoors did not affect pasture use, but resulted in an increase in TMR intake of $2.2 \pm 0.41 \mathrm{~kg}$ of dry
\end{abstract}

Received January 12, 2011.

Accepted March 30, 2011.

${ }^{1}$ Corresponding author: smrutter@harper-adams.ac.uk matter/d. The cows spent more time on pasture as the temperature-humidity index indoors $(55.6 \pm 0.92)$ and outdoors $(54.6 \pm 0.82)$ increased, but rainfall and milk yield did not influence preference. Cows with lameness score $>1.5$ spent more time indoors $(35.4 \pm 4.52$ vs. $25.2 \pm 2.64 \%$ for cows with $>1.5$ vs. $\leq 1.5$ lameness score, respectively). In conclusion, the cows expressed a partial preference for pasture, which was not influenced by providing TMR on pasture.

Key words: total mixed ration, preference, pasture, housing

\section{INTRODUCTION}

Dairy cattle are grazing animals, so pasture is a natural environment (Clutton-Brock, 1999). It allows the expression of normal behavior and can often be seen as a period of recovery for lame cows (HernandezMendo et al., 2007; Olmos et al., 2009). Feed cost and labor were decreased when cows were on pasture (Clark and Kanneganti, 1998). Yet, when high-yielding dairy cows are only provided with pasture to graze, they may not be able to meet their nutritional demands (Fike et al., 2003), and grazing alone could compromise their freedom from hunger, and limit productivity. Fontaneli et al. (2005) reported that cows on pasture produced $19 \%$ less milk than those in confined housing, and this is often the reason dairy cows are kept indoors. When dairy cows are housed they are generally provided with a high-quality diet, which allows them to more easily meet their nutritional demands and their production potential. Indoor housing systems raise other welfare concerns. The incidence of mastitis is higher indoors (Washburn et al., 2002), natural behavior may be restricted (Boyle et al., 2008), and space allowance is often decreased. Haskell et al. (2006) found that hoof disorders and lameness were higher for cows housed indoors, compared with those on pasture.

Indoor housing provides protection from environmental conditions and studies that have offered cows a choice of where to spend their time have shown that animals spend more time indoors as the temperature 
humidity index increases (Legrand et al., 2009), as the season progresses from summer into winter (Krohn et al., 1992), and on days when it rains (Charlton et al., 2011). Legrand et al. (2009) reported that although cows grazed on pasture, they used the indoor housing predominately for feeding, especially after morning and afternoon milking. Despite using the indoor housing for food and protection, cattle have demonstrated a preference for pasture. Krohn et al. (1992) found that during the summer months, cows spent $72 \%$ of their time on pasture. Similarly, Legrand et al. (2009) found that dairy cows had a preference for pasture during the nighttime. Pasture seems the preferred lying place for dairy cows, as they spent over $80 \%$ of their lying time on pasture when given a choice (Ketelaar-de Lauwere et al., 1999), particularly when the pasture was close (50 $\mathrm{m})$ to the indoor housing (Spörndly and Wredle, 2004). In contrast to these findings, Charlton et al. (2011) reported that cows spent $91.9 \%$ of their time indoors when given a choice to be indoors or on pasture. Milk yield influenced choice, with high-yielding cows $(>26.9$ $\mathrm{kg} / \mathrm{d}$ ) spending more time indoors compared with lower yielding animals $(\leq 26.9 \mathrm{~kg} / \mathrm{d})$. It was suggested that the provision of TMR indoors may have been the primary influence for the high-yielding dairy cows to spend more time indoors as they could more easily meet their nutritional demands.

The current study aimed to investigate the effect of providing dairy cattle with TMR indoors and on pasture. It was hypothesized that cows provided with access to TMR indoors and on pasture would spend more time on pasture compared with the control group with access to TMR indoors only, as cows will be able to spend their time on pasture and meet their nutritional demands from the TMR.

\section{MATERIALS AND METHODS}

\section{Animals and Management}

Thirty-six pregnant Holstein-Friesian dairy cows $(8$ primiparous and 28 multiparous) in late lactation (240 \pm 8.46 DIM, mean \pm SEM), producing between 7.3 to $45.4 \mathrm{~kg} / \mathrm{d}$, with a BCS of $3.0 \pm 0.05$ from the herd at Harper Adams University College, Shropshire, UK $\left(52^{\circ} 47^{\prime} \mathrm{N} ; 2^{\circ} 26^{\prime} \mathrm{W}\right)$ were selected based on milk yield and allocated to 1 of 3 study groups $(\mathrm{n}=12 \times 3)$. Within each group the cows were further divided into 2 groups: group 1 (treatment group; $\mathrm{n}=6$ ), which had access to TMR indoors and on pasture, and group 2 (control group; $\mathrm{n}=6$ ), which only had access to TMR indoors. Initially the cows were divided into groups using random allocation. If a significant difference existed between the milk yields of the 2 groups, they were reselected until no significant difference occurred. Each study period lasted for $26 \mathrm{~d}$, which consisted of a 7-d training period followed by a 6 -d measurement period. Within each study period a crossover design was used, so on d 14 cows were rotated between treatments. Twice daily at 0430 and $1500 \mathrm{~h}$ the cows were taken to the milking parlor by their regular stockperson and milked through a 40-point internal rotary parlor. No concentrates were fed during milking.

The experiment was conducted between August 17 to November 6, 2009 (study period 1: August 17 to September 11, 2009; study period 2: September 14 to October 9, 2009; and study period 3: October 12 to November 6, 2009). Prior to the study the cows were housed indoors in a freestall barn from November to April and allowed access to pasture from April to October, depending on the weather conditions. Ethical approval for the study was given by the Harper Adams University College Research Ethics Committee.

\section{Experimental Design}

Following both milkings, the 12 cows were automatically separated into a holding area, using an automatic segregation gate (Westfalia Surge Ltd., Milton Keynes, UK). At approximately 0645 and $1700 \mathrm{~h}$, the cows were taken from the holding area and moved to a choice point, which was equidistant $(20 \mathrm{~m})$ between the housing and pasture (Figure 1). At the choice point, the group of cows could choose whether to go indoors or to pasture, and their initial decision recorded. The cows were then free to move to and from each location between milkings. A Voltek night vision video camera (KT\&C Co., Ltd., Seoul, South Korea) connected to a video cassette recorder (Sony SVT-124P; Sony, Tokyo, Japan) located on the pathway was used to continuously record cow movement between the housing and pasture.

Cows assigned to the treatment group had access to TMR indoors and on pasture, whereas control cows only had access to TMR indoors. The TMR indoors was available from electronic RIC feed bins (Insentec, Marknesse, the Netherlands; Jackson et al., 2004). On pasture, cows had access to the TMR through a Calan gate feeding system (American Calan, Inc., Northwood, $\mathrm{NH}$ ). Both the treatment and control groups could graze the pasture. Prior to the study all of the cows had experience with the indoor housing and pasture.

Indoor Housing. The indoor area $\left(206 \mathrm{~m}^{2}\right.$; freestalls; Figure 1) was part of a larger housing area and was connected to the pasture through a $4.0-\mathrm{m}$ gate at the end of the barn. The indoor area had 2 passageways, both with automatic scrapers, set to run every $3 \mathrm{~h}$. A 4.0-m wide passage allowed access to 12 RIC bins (1.0 


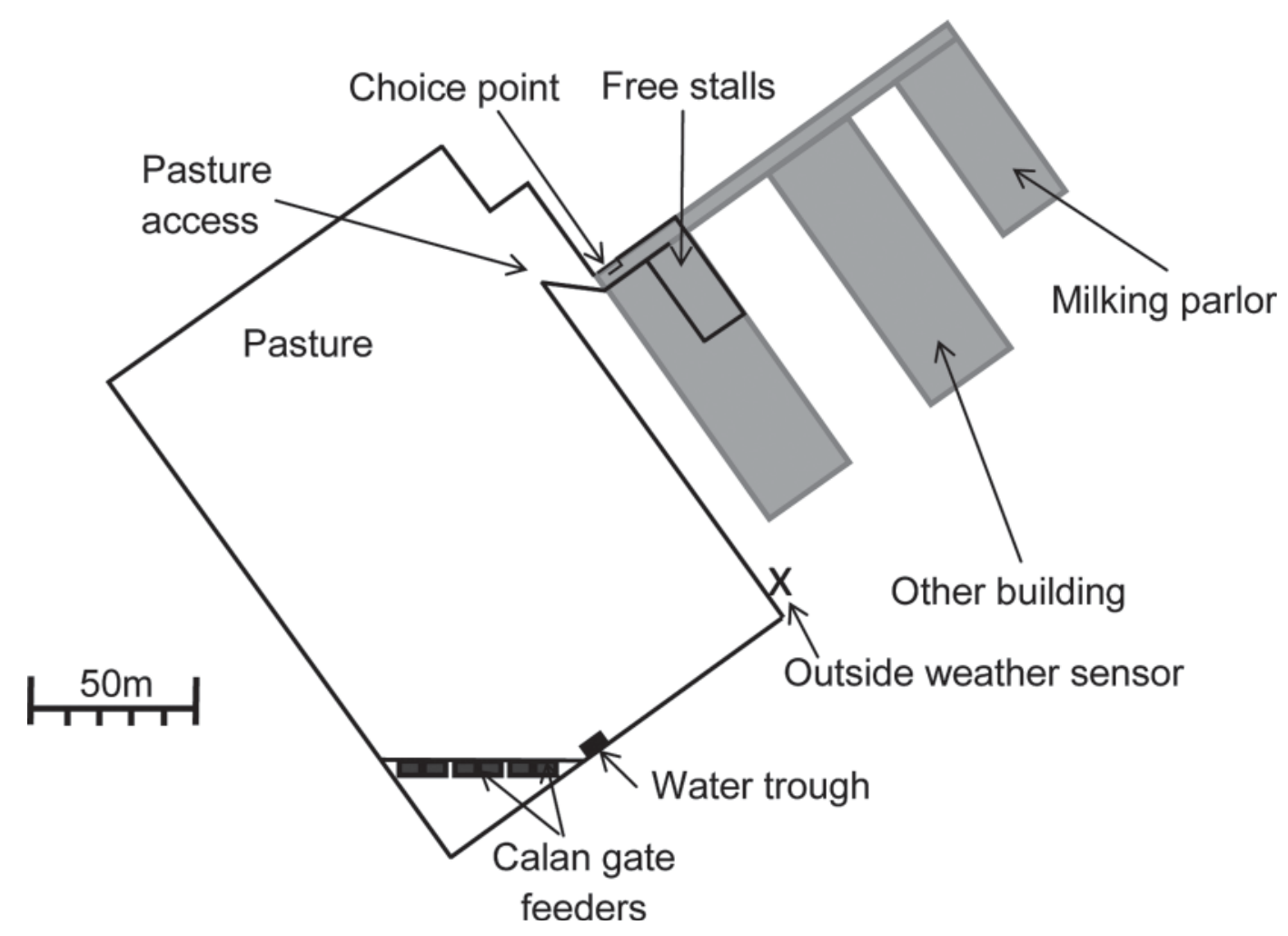

Figure 1. Plan of the experimental area showing the position of the indoor housing with freestalls in relation to the pasture, the choice point [equidistant $(20 \mathrm{~m})$ between the indoor housing and pasture], the position of the Calan gate feeders and water trough on pasture, and the outdoor weather sensor.

$\times 0.9 \times 0.8 \mathrm{~m})$ where all of the cows had ad libitum access to a TMR (DM basis: $25 \%$ corn silage, $14 \%$ grass silage, $10 \%$ whole crop wheat, $14 \%$ caustic barley, $12 \%$ dried molasses sugar beet shreds, $12 \%$ high-protein soya, $7 \%$ rapeseed meal, $2 \%$ molasses, $2 \%$ protected fat, $1 \%$ minerals, $0.5 \%$ limestone, $0.5 \%$ urea). The chemical composition was $48.7 \% \mathrm{DM}, 12.2 \mathrm{MJ}$ of $\mathrm{ME} / \mathrm{kg}$ of DM, $17.6 \% \mathrm{CP}$ in DM, 30.0\% NDF in DM, $18.7 \%$ starch in DM, and $7.6 \%$ sugar in DM. The cows could access feed from any of the 12 bins. A transponder attached to a collar and weigh cells located in the bins allowed individual feed intake to be measured. Fresh food was provided in the bin daily at approximately $1100 \mathrm{~h}$. Feed refusals were removed from the bins every Monday and Thursday morning. The adjacent $3.7-\mathrm{m}$ passageway allowed access to $182.7 \times 1.2 \mathrm{~m}$ freestalls with 3 -cm thick rubber mattresses, which were bedded with lime ash 3 times weekly. Fresh drinking water was available ad libitum from $21.7 \times 0.5 \times 0.5 \mathrm{~m}$ water troughs at the end of the barn, which were $6.7 \mathrm{~m}$ from the nearest RIC bin.

Pasture. The cows had access to a 1.5-ha field, which was fenced off using electric fencing tape (pasture; Figure 1). The grazing area consisted predominantly of a permanent mixed perennial ryegrass and white clover sward. At the far end of the field, six $1.2 \times 1.4 \mathrm{~m}$ Calan gate feeders were placed in pairs, separated by a $1.5-\mathrm{m}$ gate (Calan gate feeders; Figure 1). Each pair of gates was covered with a $2.7 \times 2.7 \mathrm{~m}$ high gazebo to keep the TMR dry. Cows in the treatment group could access feed from the Calan feeders using a transponder that was attached to a separate collar worn by the cows. Each cow was trained to use an individual feeder. Fresh TMR (same composition as indoors) was placed in a 0.7 $\times 0.6 \times 0.4 \mathrm{~m}$ feed bin at the back of each gate daily, at approximately $1100 \mathrm{~h}$. To measure feed intake, refusals from the previous day were removed and weighed. At $1700 \mathrm{~h}$, the feed bins were checked. If more than half of the feed had been eaten, another $10 \mathrm{~kg}$ of feed was added to the bin. Fresh drinking water was available ad libitum from a $1.3 \times 0.5 \times 0.5 \mathrm{~m}$ water trough, situated $8.4 \mathrm{~m}$ from the nearest Calan gate (Figure 1).

Training the Cows. Each experimental period consisted of two 7-d training periods. During this time, the cows were trained to use the Calan gate feeders, the RIC bins, and to habituate to choosing whether to go indoors or to pasture. To train the cows to use the Calan gate feeders, the 6 treatment cows were separated from the control cows on d 1 to 4 of the training period, at approximately $1100 \mathrm{~h}$ (when fresh 
TMR was provided). During this time, the behavior of the cows was shaped. This was achieved by opening the Calan gate as the cow approached the correct feeder. This was repeated several times until each cow was repeatedly approaching the correct gate and eating from the feeder. After this, if the cows left, the feeder the spring-loaded gate would close and lock, and the cows could then only gain access by using their transponder to open the lock, which was a solenoid operated bolt. A similar approach was used to train the cows to use the RIC bins. The cows were then observed to ensure they could successfully open the Calan gates and RIC feeders using their transponder and where eating from the feeder. All cows were successfully trained to use the Calan gates and RIC bins within $4 \mathrm{~d}$.

\section{Measurements}

Manual Behavior Observations. All behavioral activities and positions were recorded for approximately $12 \mathrm{~h} / \mathrm{d}$ (during the hours of daylight), every other day throughout the measurement period for the 12 cows, whether they were on pasture, indoors, or on the pathway between the locations. Manual observations of behavior occurred every 5 min during each observational period. Binoculars were used by the observer to ensure accurate identification of each cow with minimum disturbance. During each 5-min observation period the observer recorded the following activities, once for each cow: (1) location: indoors, pasture, or pathway between indoors and pasture; (2) position: lying, standing, or walking; (3) jaw activity: eating (TMR indoors or on pasture), grazing, ruminating, drinking, or idling (i.e., none of the preceding jaw activity categories); and (4) other: grooming, social interaction, investigating, estrus, play, and aggression.

Weather Conditions. Weather conditions were recorded automatically every $15 \mathrm{~min}, 24 \mathrm{~h} / \mathrm{d}$ throughout the training and study period using a Davis Vantage PRO2 weather recorder (Davis Instruments Corp., Hayward, CA). Ambient temperature $\left({ }^{\circ} \mathrm{C}\right)$ and relative humidity (\%) were recorded indoors and ambient temperature $\left({ }^{\circ} \mathrm{C}\right)$, relative humidity (\%), wind speed $(\mathrm{m} / \mathrm{s})$, wind direction, and rainfall $(\mathrm{mm})$ were recorded outdoors (outside weather sensors; Figure 1). Data were downloaded weekly. The temperature-humidity index (THI) was calculated as THI $=(1.8 \mathrm{~T}+32)-[(0.55$ $-0.0055 \mathrm{RH}) \times(1.8 \mathrm{~T}-26)]$ (National Oceanic and Atmospheric Administration, 1976), with $\mathrm{T}=$ ambient temperature $\left({ }^{\circ} \mathrm{C}\right)$ and $\mathrm{RH}=$ relative humidity $(\%)$.

Performance and Lameness. Milk yield was recorded automatically for each cow at each milking by a computerized recording system (Westfalia Surge Ltd.) throughout the study and training periods.
On d 1, 13, and 26 of the study period, a BCS of 1 to 5 was assigned to each cow according to Edmonson et al. (1989). At the same time a lameness score was given to each cow, according to Flower and Weary (2006). A lameness score of 1 (smooth and fluid movement) to 5 (ability to move is severely restricted and must be vigorously encouraged to move) was given as each cow was walked along a concrete floored area. The BCS and lameness scoring at each stage were carried out by the same person at approximately $1645 \mathrm{~h}$.

Sward Height. Measurements of compressed sward height were made each day at approximately $0630 \mathrm{~h}$ using a rising plate meter (Ashgrove Pasture Meter; Ashgrove Pastoral Products, Hamilton, NZ). The rising plate meter was placed randomly around the field 30 times in a $\mathrm{W}$ pattern, with 7 paces between each measurement. The measurements of compressed sward height were used to estimate the amount of herbage in the field, with $\mathrm{kg}$ of $\mathrm{DM} / \mathrm{ha}$ calculated using the following regression equation: herbage mass $(\mathrm{kg}$ of DM/ha) $=$ [sward height $(\mathrm{cm}) \times 316]+300$ (Sayers et al., 2003). The field was maintained to provide between 1800 and $3000 \mathrm{~kg}$ of DM/ha. Throughout the study, the sward height was $7.2 \pm 0.45 \mathrm{~cm}$, providing $2,568 \pm 46.3 \mathrm{~kg}$ of $\mathrm{DM} / \mathrm{ha}$.

\section{Statistical Analysis}

Decision from the choice point and time spent in each location was analyzed for individual cows $(\mathrm{n}=36)$ during each 6-d study period using a 1-sample $t$-test. Percentage decision to go indoors from the choice point and time spent on pasture was analyzed to determine whether it was significantly different from 0,50 , and $100 \%$ [i.e., choice to go to pasture; indifferent (i.e., random choice); or to go indoors, respectively].

Paired $t$-tests were used to compare time budgets indoors and on pasture. Analysis of variance was used to analyze the effect of the treatment on decision at the choice point, overall time spent on pasture, pasture use during the day time and night time, the number of transitions between indoors and pasture, the consumption of TMR, and milk yield during each 6-d measurement period. The model included the effect of study period, treatment, the interaction between study period and treatment and the block of each animal. Prior to analysis the data were checked for normality using probability distribution plots. Data which were not normally distributed were transformed using a logit-transformation. All means $( \pm \mathrm{SEM})$ are presented as untransformed data. Linear regressions were used to determine whether a relationship existed between weather condition and animal factors and the percentage time spent indoors and on pasture. GenStat was 
Table 1. Effect of treatment on time spent on pasture $(\% \pm$ SEM) by dairy cows $(\mathrm{n}=36)$, decision to go indoors from the choice point $(\% \pm$ SEM), consumption of TMR ( $\mathrm{kg}$ of DM \pm SEM), behavioral activity $(\%$ $\pm \mathrm{SEM})$, and milk yield $(\mathrm{kg} \pm \mathrm{SEM})$

\begin{tabular}{|c|c|c|c|}
\hline Item & Control $^{1}$ & Treatment $^{2}$ & $P$-value \\
\hline \multicolumn{4}{|l|}{ Time spent (over $24 \mathrm{~h}$ ) } \\
\hline Overall time spent on pasture (\%) & $70.3 \pm 2.67$ & $71.9 \pm 2.49$ & 0.298 \\
\hline Daytime pasture use (\%) & $49.8 \pm 4.95$ & $53.0 \pm 4.44$ & 0.113 \\
\hline Nighttime pasture use (\%) & $83.8 \pm 1.93$ & $84.0 \pm 2.51$ & 0.364 \\
\hline Transitions between indoors and pasture (n) & $2.7 \pm 0.19$ & $2.6 \pm 0.17$ & 0.560 \\
\hline Decision at the choice point (\% indoors) & $96.3 \pm 0.15$ & $96.5 \pm 0.12$ & 0.867 \\
\hline \multicolumn{4}{|l|}{ TMR consumption and milk yield } \\
\hline Consumption of TMR indoors ( $\mathrm{kg}$ of $\mathrm{DM})$ & $16.7 \pm 0.61$ & $14.5 \pm 0.78$ & $<0.001$ \\
\hline Consumption of TMR outside ( $\mathrm{kg}$ of $\mathrm{DM}$ ) & $0.0 \pm 0.00$ & $4.4 \pm 0.65$ & \\
\hline Overall consumption of TMR ( $\mathrm{kg}$ of DM) & $16.7 \pm 0.61$ & $18.9 \pm 0.57$ & $<0.001$ \\
\hline Milk yield $(\mathrm{kg})$ & $24.5 \pm 1.37$ & $24.8 \pm 1.35$ & 0.550 \\
\hline \multicolumn{4}{|l|}{ Behavioral activity during daylight hours (\%) } \\
\hline Grazing & $16.1 \pm 2.07$ & $14.2 \pm 1.42$ & 0.318 \\
\hline Eating TMR indoors & $17.7 \pm 0.95$ & $16.2 \pm 1.1$ & 0.120 \\
\hline Eating TMR outdoors & $0.0 \pm 0.00$ & $4.6 \pm 0.68$ & \\
\hline Ruminating indoors & $11.9 \pm 1.85$ & $11.1 \pm 1.62$ & 0.464 \\
\hline Ruminating on pasture & $11.6 \pm 1.18$ & $11.9 \pm 1.09$ & 0.730 \\
\hline Idling indoors & $19.2 \pm 2.38$ & $19.5 \pm 2.16$ & 0.834 \\
\hline Idling on pasture & $17.6 \pm 1.79$ & $19.2 \pm 1.83$ & 0.280 \\
\hline Drinking indoors & $1.2 \pm 0.13$ & $1.0 \pm 0.09$ & 0.024 \\
\hline Drinking on pasture & $0.3 \pm 0.07$ & $0.4 \pm 0.06$ & 0.470 \\
\hline
\end{tabular}

${ }^{1}$ Cows had access to TMR indoors only.

${ }^{2}$ Cows had access to TMR indoors and on pasture.

used to analyze all data (GenStat 12th edition; Lawes Agricultural Trust Co. Ltd., Rothamsted, UK).

\section{RESULTS}

\section{Time Spent Indoors and on Pasture}

The cows spent more time on pasture than indoors $(71.1 \pm 1.82$ vs. $28.9 \pm 1.82 \%$ for pasture vs. indoors, respectively) which was different from $0 \%(t=39.10, P$ $<0.001), 50 \%(t=11.60, P<0.001)$, and $100 \%(t=$ $-15.89, P<0.001$; Table 1 ). Providing the cows with TMR indoors and outdoors did not influence pasture use. The cows spent more time on pasture during the night than the day $(83.9 \pm 1.57$ vs. $51.4 \pm 3.31 \%$ time on pasture for night vs. daytime, respectively; $P<$ $0.001)$. No difference was observed $(P>0.05)$ between the use of pasture by treatment and control cows during the daytime or night. The cows made $2.7 \pm 0.13$ transitions between the indoor housing and pasture (excluding the times the cows were brought indoors for morning and afternoon milking), which was not influenced by treatment. Study period had an effect on overall time spent on pasture, with cows decreasing pasture use as the study progressed (Table 2). Daytime and nighttime pasture use was influenced by the study period; pasture use during the day time (a.m. to p.m. milking) started to decrease during the second study period, whereas nighttime (p.m. to a.m. milking) pasture use only started to decrease during the third study period (Table 2).

\section{Decision from the Choice Point}

From the choice point, the cows chose to go indoors more often than they chose to go to pasture (96.4 \pm 0.80 vs. $3.6 \pm 0.80 \%$, respectively), which was different from $0 \%(t=38.46, P<0.001)$ and $50 \%(t=18.52$, $P<0.001)$, but not different from $100 \%(t=-1.43$, $P=0.212$; Table 1). No difference was observed at the choice point for treatment or control cows. Study period influenced the decision at the choice point $(P<$ 0.001 ), with decision to go to pasture increasing during study period 3 (Table 2).

\section{Consumption of TMR Indoors and on Pasture}

When cows had access to TMR indoors and on pasture, the overall consumption of TMR increased (Table 1). Cows receiving the control treatment ate more TMR indoors than did treatment cows. Study period influenced the amount of TMR consumed indoors and the overall consumption of TMR ( $\mathrm{kg}$ of DM), with TMR intake increasing as the study progressed (Table 2). An interaction existed between the treatment and study period $(P=0.024)$, with control cows increasing DMI in study period 3. The total consumption of TMR ( $\mathrm{kg}$ of DM) was influenced by milk yield $\left(\mathrm{R}^{2}=0.29, P<0.001\right)$ with high-yielding dairy cows (producing $>24.3 \mathrm{~kg} / \mathrm{d}$ ) consuming more TMR than low-yielding dairy cows $(\leq 24.3 \mathrm{~kg} / \mathrm{d} ; 19.4 \pm 0.60$ vs. $16.2 \pm 0.51 \mathrm{~kg}$ of $\mathrm{DM}$, for high- vs. low-yielding cows, respectively). 
Table 2. Effect of study period on time spent on pasture (\% \pm SEM) by dairy cows $(\mathrm{n}=36)$, decision to go indoors from the choice point $(\%$ $\pm \mathrm{SEM})$, consumption of TMR ( $\mathrm{kg}$ of $\mathrm{DM} \pm \mathrm{SEM})$, behavioral activity $(\% \pm \mathrm{SEM})$, and milk yield $(\mathrm{kg} \pm \mathrm{SEM})$

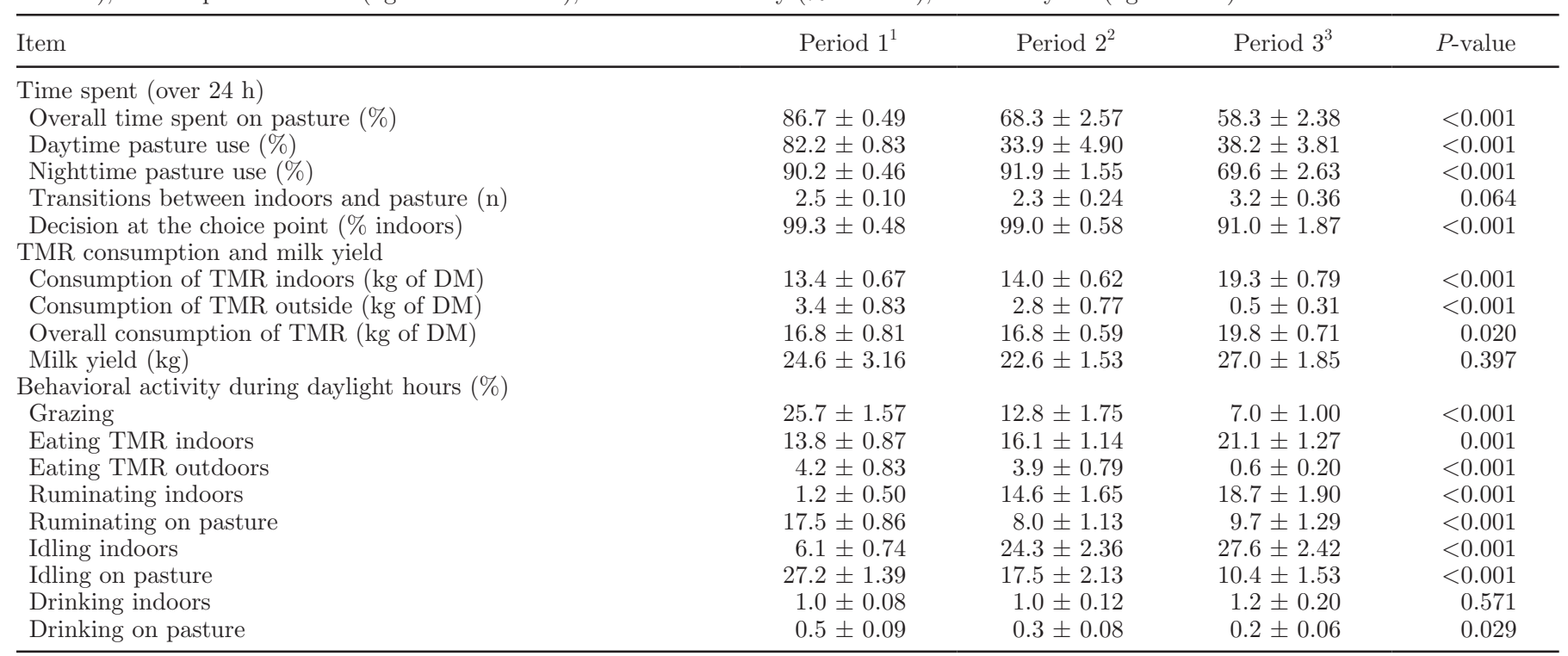

${ }^{1}$ Study period 1 carried out from August 17 to September 11, $2009(\mathrm{n}=12)$.

${ }^{2}$ Study period 2 carried out from September 14 to October 9, $2009(\mathrm{n}=12)$.

${ }^{3}$ Study period 3 carried out from October 12 to November 6, $2009(\mathrm{n}=12)$.

\section{Behavioral Activity (During Daylight Hours)}

The behavior observations revealed that during daylight hours, the cows spent $48.9 \%$ of their time indoors, $48.4 \%$ of their time on pasture, and $2.6 \%$ on the pathway between the 2 locations (Table 3 ). Treatment did not influence time spent eating TMR, grazing, ruminating, or drinking (Table 1). The cows spent more time eating TMR when indoors than on pasture (Table 3 ). Time spent drinking indoors was greater than that on pasture, but no difference was observed in idling or rumination time indoors or on pasture. Overall, eating time indoors increased with each study period and grazing time decreased (Table 2).

Of the time spent eating indoors, $32.3 \pm 1.25 \%$ was in the first hour following the a.m. decision at the choice point and $29.9 \pm 1.44 \%$ in the first hour following the p.m. decision at the choice point, but this eating time decreased with study period (Figure 2). In study period 1 , the cows spent longer eating and then went to pasture, whereas in study period 3 the cows spent less time eating when they first returned from milking and stayed inside.

The cows spent $52.9 \%$ of their time standing and $43.8 \%$ lying (Table 3 ). Time spent standing and lying was not different when indoors or on pasture. Of the $3.3 \%$ of time spent walking, more time was spent walking on pasture than indoors. The cows did not lie on the pathway between the 2 locations, but they did spend $2.1 \%$ of their time standing on the pathway and $0.5 \%$ of time walking on the pathway.

Table 3. Mean percentage $( \pm \mathrm{SEM})$ of time cows $(\mathrm{n}=36)$ spent performing each behavioral activity indoors and on pasture during daylight hours when they had a choice between the 2 locations

\begin{tabular}{|c|c|c|c|c|c|}
\hline Item & Indoors & Pasture & Overall $^{1}$ & $t$-value & $P$-value \\
\hline Overall time spent (\%) & $48.9 \pm 2.97$ & $48.5 \pm 2.93$ & $100 \pm 0.00$ & 0.09 & 0.930 \\
\hline Eating TMR (\%) & $17.0 \pm 0.73$ & $2.9 \pm 0.43$ & $19.9 \pm 0.71$ & 14.68 & $<0.001$ \\
\hline Grazing (\%) & $\mathrm{NA}^{2}$ & $15.2 \pm 1.25$ & $15.2 \pm 1.25$ & & \\
\hline Ruminating (\%) & $11.5 \pm 1.22$ & $11.7 \pm 0.80$ & $23.6 \pm 0.71$ & -0.13 & 0.895 \\
\hline Idling (\%) & $19.3 \pm 1.60$ & $18.3 \pm 1.28$ & $39.9 \pm 0.85$ & 0.35 & 0.730 \\
\hline Drinking (\%) & $1.1 \pm 0.08$ & $0.4 \pm 0.05$ & $1.5 \pm 0.09$ & 6.92 & $<0.001$ \\
\hline Standing (\%) & $26.7 \pm 1.14$ & $24.1 \pm 1.61$ & $52.9 \pm 1.28$ & 1.04 & 0.303 \\
\hline Lying (\%) & $21.2 \pm 2.38$ & $22.6 \pm 1.62$ & $43.8 \pm 1.38$ & -0.36 & 0.718 \\
\hline Walking (\%) & $1.0 \pm 0.08$ & $1.8 \pm 0.16$ & $3.3 \pm 0.18$ & -3.83 & $<0.001$ \\
\hline
\end{tabular}

${ }^{1}$ Time spent indoors, on pasture, and on the track between the 2 locations.

${ }^{2}$ Not applicable. 


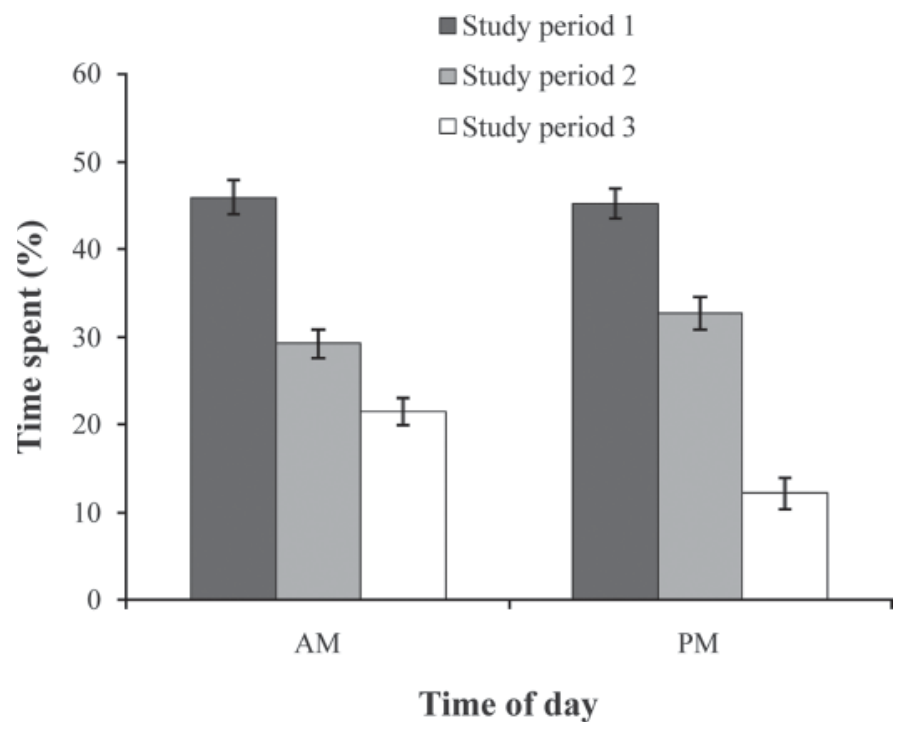

Figure 2. The proportion ( $\pm \mathrm{SEM})$ of indoor eating time spent eating within the first hour following milking for each study period.

\section{Factors Affecting Preference}

Throughout the study, the average temperature was $13.5^{\circ} \mathrm{C}$ indoors and $12.4^{\circ} \mathrm{C}$ outdoors (range from 6.3 to $22.4^{\circ} \mathrm{C}$ ). The THI was $55.6 \pm 0.92$ indoors and $54.6 \pm$ 0.82 outdoors. The time on pasture increased as THI increased indoors $\left(\mathrm{y}=1.5372 \mathrm{x}-14.271 ; \mathrm{R}^{2}=0.33, \mathrm{n}=\right.$ $36 \mathrm{~d}, P<0.001$; Figure 3$)$ and outdoors $(\mathrm{y}=1.2695 \mathrm{x}+$ $1.9129, \mathrm{R}^{2}=0.18, \mathrm{n}=36 \mathrm{~d}, P=0.012$ ). When the THI indoors was $>55.6$, the cows spent $79.3 \%$ of their time on pasture, compared with $64.2 \%$ when the indoor THI was $\leq 55.6$. It rained on 19 of the 36 study days, but rainfall $(2.1 \pm 0.58 \mathrm{~mm})$ did not influence preference $(P=0.183)$.

Milk yield did not influence time spent on pasture $(24.3 \pm 0.98 \mathrm{~kg} / \mathrm{d} ; P=0.743)$. Although treatment cows had access to TMR indoors and on pasture, no difference existed $(P>0.05)$ in milk yield between control and treatment cows (Table 1), and milk yield did not differ between study periods (Table 2). Lactation number $(2.6 \pm 0.19)$ had no effect $(P=0.693)$ on cow preference to be indoors or on pasture. Lameness score $(1.5 \pm 0.09$; range 1 to 3.5$)$ influenced where the cows spent their time $\left(\mathrm{y}=-8.474 \mathrm{x}+84.203, \mathrm{R}^{2}=0.12\right.$, $\mathrm{n}=36, P<0.001$ ); cows with a lameness score $>1.5$ spent more time indoors compared with those with a low lameness score $(\leq 1.5)$. A tendency existed $(P$ $=0.092)$ for cows with a high BCS $(>3.0)$ to spend more time on pasture (13:33 vs. 14:02 h for low vs. high BCS, respectively) compared with cows with a low BCS $(\leq 3.0)$. The BCS was $3.0 \pm 0.05$ over the study period.

\section{DISCUSSION}

The cows expressed a $71 \%$ partial preference to be on pasture, which was not influenced by providing TMR outdoors, supporting Krohn et al. (1992), who reported that cows spent $72 \%$ of their time outdoors during the summer months when given a choice. These findings are contradictory to those of Charlton et al. (2011), which showed that cows expressed a partial preference for indoors, spending over $90 \%$ of their time inside when given a choice. It is possible that the rearing of the cows and their previous experience could have influenced preference. In the study by Charlton et al. (2011), the cows had been reared indoors and had little experience of pasture before the study, whereas in the current study the cows had been reared mainly outdoors and had access to pasture during the summer months. Alternatively, the distance between indoor housing and pasture could have influenced preference, as cows in the current study had to walk $40 \mathrm{~m}$ between the housing and pasture, whereas in Charlton et al. (2011) $96 \mathrm{~m}$ separated the 2 locations. As the provision of TMR on pasture did not influence pasture use in the current study, it is possible that the short distance between indoors and pasture allowed the cows to spend time outside and return indoors to eat. Transitions between the housing and pasture (2.7) were higher in the current study than 1.8 reported in Charlton et al. (2011). The effect of rearing and distance between indoor housing and pasture on the preference of dairy cows to be indoors or on pasture requires further investigation.

Following a.m. and p.m. milkings, the cows almost always chose indoors. It is likely they chose to go indoors to eat, as they spent more than half their total eating time consuming TMR indoors following milkings. Legrand et al. (2009) found that feeding time peaked

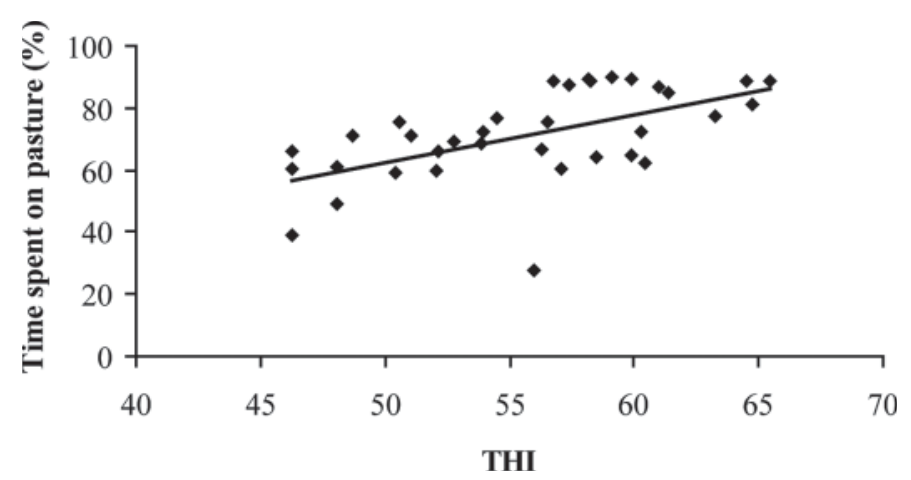

Figure 3. Mean percentage of time cows spent outside when they had a choice to be indoors or on pasture in relation to the average daily temperature humidity index (THI). 
immediately after milking. When eating, cows prefer to stand on softer surfaces, rather than concrete (Tucker et al., 2006), which would lead to the expectation that cows offered TMR while standing on concrete flooring or on pasture would choose pasture. Yet, the cows spent more time consuming TMR indoors. One explanation is the distance to the feed from the choice point, as the cows had to walk $179 \mathrm{~m}$ to the Calan gates and only $26 \mathrm{~m}$ to the RIC bins from the choice point. Previous experience of the cows may have influenced preference (Keeling and Jensen, 2002), as the cows had not eaten TMR on pasture before the study, yet they were used to eating TMR indoors.

On pasture, fresh TMR was provided daily and feed refusals from the previous day were removed, so individual feed intake could be measured. Indoors, the electronic feed bins automatically measured individual intakes, so feed refusals were removed twice per week, and on the remaining days, fresh TMR was placed on top of any remaining food. Fresh feed is a primary factor influencing feeding (DeVries and von Keyserlingk, 2005), so this practice may have affected feeding behavior. It is possible that the cows chose to eat TMR on pasture once the fresh TMR indoors was consumed.

The eating time of $4.2 \mathrm{~h}$ (TMR indoors, TMR on pasture, plus grazing) during the daytime supported the $4.8 \mathrm{~h}$ of eating time reported by Charlton et al. (2011) when cows had a choice to be indoors or on pasture, but lower than $5.3 \mathrm{~h}$ reported by Krohn et al. (1992). Differences in eating time between the studies may be because of the ratio of time spent eating TMR or grazing, as Krohn et al. (1992) reported 4 of $5.3 \mathrm{~h}$ spent grazing, which was more than double the $1.8 \mathrm{~h}$ in the current study. In the current study, DMI from grazing was not quantified. Control cows consumed more of the TMR indoors than did treatment cows, but when cows had access to TMR indoors and on pasture, the overall consumption of TMR increased by $11.6 \%$. An increase in consumption may lead to an increase in milk yield; however, the length of each study period may have been insufficient to detect any significant differences in production between control and treatment cows.

Study period influenced preference and eating times, with pasture use and grazing decreasing, and eating time indoors increasing over time, supporting the finding by Krohn et al. (1992) that cows prefer indoors as the season progresses from summer to winter. Cows in study period 2 decreased daytime pasture use to less than half that of study period 1 , a value that remained similarly low for study period 3. Ketelaar-de Lauwere et al. (2000) reported increased eating times when cows where offered fresh pasture, but over time eating decreased. At the beginning of study period 1, the cows were placed on fresh pasture, but as the study was carried out during the late grazing season, the grass quality may have decreased, resulting in a decrease in pasture use and time spent grazing. Cows will often consume the majority of their feed during the daytime (Albright and Arave, 1997), and will avoid grazing areas with a low nutritious value (Hessle et al., 2008), so they may have decreased daytime pasture use as the grass quality decreased, so they could be indoors, nearer the TMR, where it may have been easier for them to reach their nutritional demands. Ketelaar-de Lauwere et al. (1999) reported that cows not offered fresh pasture started to leave the grazing area and return to the barn to feed. Nighttime pasture use was over $90 \%$ for study periods 1 and 2, but decreased by approximately $20 \%$ during study period 3 , although average nighttime pasture use still remained high, with the cows spending $70 \%$ of their time outdoors during the night. Similarly, Legrand et al. (2009) observed that cows, given the choice between pasture and an indoor freestall barn, had an almost exclusive preference for pasture during the night. Ruminating and idling were influenced by the progression of the study. Cows in study period 3 spent almost $10 \%$ more time ruminating during the daytime compared with cows in study period 1 . This may be explained by the cows having more available time in study period 3 , as they spent $15 \%$ less time eating (TMR indoors, TMR on pasture, and grazing) than did cows in study period 1. Alternatively, the increase in rumination may be a result of cows in study period 3 consuming grass with a greater content of longer fiber with lower digestibility, as these factors are associated with decreased rumination efficiency (Teller et al., 1990), in association with the greater total DMI from the TMR.

Cardot et al. (2008) reported that DMI can affect drinking behavior and water intake of lactating dairy cows. More than $70 \%$ of water intake was during the daytime, and drinking activity was correlated with feeding and milking, which could explain why the cows in the current study expressed a preference to drink indoors. More than $60 \%$ of the cows' eating time was spent consuming TMR in the first hour following milking, so they would have been more likely to drink during this time indoors.

Lying times during the daytime were $5.3 \mathrm{~h}$. Spending almost half of the observed time lying supported others (Spörndly and Wredle, 2004; Legrand et al., 2009), but no difference existed in lying times indoors or on pasture, which is contrary to findings from studies that reported that cows had a clear preference for lying on pasture, rather than indoors (Krohn et al., 1992; Ketelaar-de Lauwere et al., 2000). Spörndly and Wredle (2004) observed a large proportion of cows lying between 2300 and $0300 \mathrm{~h}$. Cows in the current study 
spent most of their time on pasture during the nighttime, so lying time on pasture may have been higher, although observations were not carried out during the hours of darkness.

It has been suggested that cows can distinguish differences in underfoot comfort (Tucker et al., 2006) and prefer to stand more on comfortable flooring (Boyle et al., 2008). As pasture is often a softer, more comfortable surface (Hernandez-Mendo et al., 2007), it would have been expected that cows chose to stand longer on pasture rather than on concrete; however, no difference was observed between time spent standing indoors and on pasture. Walking time was higher on pasture than indoors, supporting previous findings (Charlton et al., 2011). This could be a result of the natural feeding behavior of cattle, which involves slowly walking forward (Broom and Fraser, 2007); indoors, forward movement is not necessary to find food, and eating is restricted at the feed fence.

Previous studies have reported a decrease in pasture use on rainy days (Charlton et al., 2011). Although it rained on more than half of the study days, rainfall did not influence time spent on pasture during the current study. The cows did spend more time on pasture as the THI increased. In contrast, Legrand et al. (2009) found that time on pasture decreased as the THI increased. The upper critical temperature for lactating dairy cows is $25^{\circ} \mathrm{C}$ (Albright and Arave, 1997) and the upper critical THI is $>72$ (Igono et al., 1992). In the current study, the temperature and THI remained within the comfort zone for dairy cows, which may explain why the cows were not motivated to move indoors to seek shade as the temperature increased (Schütz et al., 2008).

Lactation number and milk yield did not influence pasture use and no difference in milk yield existed between treatment groups or study groups. In contrast, Charlton et al. (2011) reported that cows with a higher milk yield spent more time indoors, possibly because of the provision of TMR indoors. A relationship also existed between lameness score and time spent indoors; cows with a lameness score above average spent more time indoors than those with a below average score. Although time on pasture can provide a period of recovery for lame cows (Hernandez-Mendo et al., 2007), and despite only $40 \mathrm{~m}$ between the 2 locations, lame cows may not have wanted to walk the distance from indoors to pasture with sore feet.

\section{CONCLUSIONS}

The cows expressed a $71 \%$ partial preference for pasture, which was not influenced by TMR being provided on pasture or milk yield, although the cows spent less time on pasture as the season progressed. It is pos- sible that the short distance $(40 \mathrm{~m})$ between the indoor housing and pasture allowed the cows to access the pasture and return to the indoor housing to eat the TMR. Providing TMR on pasture (as well as indoors) increased total intake of TMR, but did not influence grazing time or milk yield.

\section{ACKNOWLEDGMENTS}

The authors acknowledge the cooperation of the Harper Adams University College (Shropshire, UK) farm staff, and the technical support from Giles Vince, Nicky Naylor, Michelle Midgley, David Ferguson, Fred Baker, and Alison Weekes from Harper Adams University College. We thank Moira Harris and the PhD students Andrew Watson, Chamari Palliyeguru, and Minuka Weerasinghe for helping with behavior observations and Peter Kettlewell for statistical advice (all of Harper Adams University College). This study was supported by Silcock Fellowship for Livestock Research, Harper Adams University College and Reaseheath College (Cheshire, UK).

\section{REFERENCES}

Albright, J. L., and C. W. Arave. 1997. The Behaviour of Cattle. CAB International, Wallingford, UK.

Boyle, L. A., R. M. Boyle, and P. French. 2008. Welfare and performance of yearling dairy heifers out-wintered on a wood-chip pad or housed indoors on two levels of nutrition. Animal 2:769-778.

Broom, D. M., and A. F. Fraser. 2007. Domestic Animal Behaviour and Welfare. 4th ed. CABI Publishing, Wallingford, UK.

Cardot, V., Y. Le Roux, and S. Jurjanz. 2008. Drinking behavior of lactating dairy cows and prediction of their water intake. J. Dairy Sci. 91:2257-2264.

Charlton, G. L., S. M. Rutter, M. East, and L. A. Sinclair. 2011. Preference of dairy cows: Indoor cubicle housing with access to a total mixed ration vs. access to pasture. Appl. Anim. Behav. Sci. 130:1-9.

Clark, D. A., and V. R. Kanneganti. 1998. Grazing management systems for dairy cattle. Pages 311-334 in Grass for Dairy Cattle. J. H. Cherney and D. J. R. Cherney, ed. CABI Publishing, Wallingford, UK.

Clutton-Brock, J. 1999. A Natural History of Domesticated Mammals. 2nd ed. Cambridge University Press, Cambridge, UK.

DeVries, T. J., and M. A. G. von Keyserlingk. 2005. Time of feed delivery affects the feeding and lying patterns of dairy cows. J. Dairy Sci. 88:625-631.

Edmonson, A. J., I. J. Lean, L. D. Weaver, T. Farver, and G. Webster. 1989. A body condition scoring chart for Holstein dairy cows. J. Dairy Sci. 72:68-78.

Fike, J. H., C. R. Staples, L. E. Sollenberger, B. Macoon, and J. E. Moore. 2003. Pasture forages, supplementation rate, and stocking rate effects on dairy cow performance. J. Dairy Sci. 86:1268-1281.

Flower, F. C., and D. M. Weary. 2006. Effect of hoof pathologies on subjective assessment of dairy cow gait. J. Dairy Sci. 89:139-146.

Fontaneli, R. S., L. E. Sollenberger, R. C. Littell, and C. R. Staples. 2005. Performance of lactating dairy cows managed on pasturebased or in freestall barn-feeding systems. J. Dairy Sci. 88:12641276.

Haskell, M. J., L. J. Rennie, V. A. Bowell, M. J. Bell, and A. B. Lawrence. 2006. Housing system, milk production and zero-grazing effects on lameness and leg injuries in dairy cows. J. Dairy Sci. $89: 4259-4266$. 
Hernandez-Mendo, O., M. A. G. von Keyserlingk, D. M. Veira, and D. M. Weary. 2007. Effects of pasture on lameness in dairy cows. J. Dairy Sci. 90:1209-1214.

Hessle, A., M. Rutter, and K. Wallin. 2008. Effect of breed, season and pasture moisture gradient on foraging behaviour in cattle on semi-natural grasslands. Appl. Anim. Behav. Sci. 111:108-119.

Igono, M. O., G. Bjotvedt, and H. T. Sanford-Crane. 1992. Environmental profile and critical temperature effects on milk production of Holstein cows in desert climate. Int. J. Biometeorol. 36:77-87.

Jackson, M. A., R. J. Readman, J. A. Huntington, and L. A. Sinclair. 2004. The effect of processing at harvest and cutting height of urea-treated whole-crop wheat on performance and digestibility in dairy cows. Anim. Sci. 78:467-476.

Keeling, L., and P. Jensen. 2002. Behavioural disturbances, stress and welfare. Pages 79-98 in The Ethology of Domestic Animals; An Introductory Text. P. Jensen, ed. CABI Publishing, Wallingford, UK.

Ketelaar-de Lauwere, C. C., A. H. Ipema, C. Lokhorst, J. H. M. Metz, J. P. T. M. Noordhuizen, W. G. P. Schouten, and A. C. Smits. 2000. Effects of sward height and distance between pasture and barn on cows' visits to an automatic milking system and other behavior. Livest. Prod. Sci. 65:131-142.

Ketelaar-de Lauwere, C. C., A. H. Ipema, E. N. J. van Ouwerkerk, M. M. W. B. Hendriks, J. H. M. Metz, J. P. T. M. Noordhuizen, and W. G. P. Schouten. 1999. Voluntary automatic milking in combination with grazing of dairy cows milking frequency and effects on behaviour. Appl. Anim. Behav. Sci. 64:91-109.

Krohn, C. C., L. Munksgaard, and B. Jonasen. 1992. Behaviour of dairy cows kept in extensive (loose housing/pasture) or intensive (tie stall) Environments I. Experimental procedure, facilities, time budgets-Diurnal and seasonal conditions. Appl. Anim. Behav. Sci. 34:37-47.

Legrand, A. L., M. A. G. von Keyserlingk, and D. M. Weary. 2009. Preference and usage of pasture versus free-stall housing by lactating dairy cattle. J. Dairy Sci. 92:3651-3658.
National Oceanic and Atmospheric Administration (NOAA). 1976. Livestock hot weather stress. Regional Operations Manual Letter C-31-76. NOAA, Kansas City, MO.

Olmos, G., L. Boyle, A. Hanlon, J. Patton, J. J. Murphy, and J. F. Mee. 2009. Hoof disorders, locomotion ability and lying times of cubicle-housed compared to pasture-based dairy cows. Livest. Sci. 125:199-207.

Sayers, H. J., C. S. Mayne, and C. G. Bartram. 2003. The effect of level and type of supplement offered to grazing dairy cows on herbage intake, animal performance and rumen fermentation characteristics. Anim. Sci. 76:439-454.

Schütz, K. E., N. R. Cox, and L. R. Matthews. 2008. How important is shade to dairy cattle? Choice between shade or lying following difference levels of lying deprivation. Appl. Anim. Behav. Sci. 114:307-318.

Spörndly, E., and E. Wredle. 2004. Automatic milking and grazingEffects of distance to pasture and level of supplements on milk yield and cow behavior. J. Dairy Sci. 87:1702-1712.

Teller, E., M. Vanbelle, P. Kamatali, G. Collignon, B. Page, and B. Matatu. 1990. Effects of chewing behavior and ruminal digestion processes on voluntary intake of grass silages by lactating dairy cows. J. Anim. Sci. 68:3897-3904.

Tucker, C. B., D. M. Weary, A. M. de Passillé, B. Campbell, and J. Rushen. 2006. Flooring in front of the feed bunk affects feeding behavior and use of freestalls by dairy cows. J. Dairy Sci. 89:2065-2071.

Washburn, S. P., S. L. White, J. T. Green Jr., and G. A. Benson. 2002 Reproduction, mastitis, and body condition of seasonally calved Holstein and Jersey cows in confinement or pasture systems. J. Dairy Sci. 85:105-111. 